\title{
PANCASILA SEBAGAI ORTHODOKSI DAN ORTHOPRAKSIS DALAM KEHIDUPAN BERBANGSA DAN BERNEGARA
}

\author{
Oleh: \\ Mulyono \\ Dosen Fakultas Ilmu Budaya Universitas Diponegoro
}

\begin{abstract}
Pancasila as ideology contains many teachings about how human should relate to the others, nature and God in the life of society and the state. Pancasila's teachings believed truth and goodness by Indonesian peoples since been justified through a variety of scientificphilosophical studies. This is the meaning of Pancasila as a orthodoxy.

On the other hand, the process of modernization spur the development of science and technology and phenomenon of globalization so that dynamics and changes in society take place quickly. In the context of practical guideline, the implementation of Pancasila should adapt to the development of national and international community. The breakdown of Pancasila's values should be reconstructed continuously order to always stay relevant as problem solver and able to keep up with the the times. Revitalization and reinterpretation of Pancasila as a ideology should always be done in order to not become obsolete so abandoned by its adherents.
\end{abstract}

Keywords : orthodoxy, globalization, dynamics, relevant, revitalization, reinterpretation.

\section{PENDAHULUAN}

Pancasila dirumuskan oleh para pendiri negara dengan tujuan sebagai philosofische gronslag, yang mendasari kehidupan bangsa Indonesia dalam bernegara. Pancasila merupakan produk perenungan para pendiri negara dalam rangka mencari dan merumuskan sistem nilai sebagai acuan dalam praktik kehidupan bermasyarakat, berbangsa dan bernegara. Konsekuensinya, Pancasila harus dipahami sebagai suatu orthodoksi, yaitu ajaran yang diyakini sebagai yang benar dan digali lewat daya penalaran. Pancasila, sebagai orthodoksi, digali dan dirumuskan dari nilai-nilai kehidupan yang terpapar dalam sejarah kebudayaan Indonesia, sehingga Pancasila merupakan identitas atau jati diri bangsa Indonesia (Mulyono, 2008: 1). Istilah "orthodoksi" berasal dari bahasa Yunani "orthos" (yang berarti lurus) dan "doxa" (yang berarti sangka, ajaran). Orthodoksi secara harafiah berarti dengan ketegaran lurus pada ajaran. Istilah "orthopraksis" juga berasal dari bahasa Yunani "orthos" dan "praxis" (yang berarti tindakan), sehingga orthopraksis secara harafiah berarti tindakan yang lurus.

Pancasila mengandung juga unsur pergerakan dan harapan terwujudnya masyarakat ideal. Pancasila bukanlah sistem pemikiran yang teoritis-spekulatif belaka, yang bersifat statis, melainkan Pancasila dituntut sungguh nyata dalam praktik kehidupan masyarakat yang berkembang secara dinamis. Pancasila diharapkan terealisasi secara konsisten, kontekstual dan partisipatif dalam praktik hidup bangsa Indonesia. Dengan demikian, Pancasila harus juga dipahami sebagai orthopraksis.

Keadaan dan situasi dunia, sejak akhir tahun 1980-an dengan fenomena "bangkrutnya" ideologi komunisme di 
Eropa Timur dan ekspansifnya sistem kapitalisme, menjadi tantangan bagi ideologi Pancasila dan masyarakat pengunanya untuk bertahan dan berkembang mengikuti dinamika kehidupan masyarakat nasional maupun global. Bangsa Indonesia ditantang dan diuji agar mampu menjaga Pancasila selalu relevan sebagai pedoman dalam menjawab persoalan-persoalan dalam kehidupan bermasyarakat, berbangsa dan bernegara. Bung Karno pernah menegaskan, bahwa agar Pancasila kokoh bertahan dan mampu mengikuti perkembangan zaman, maka Pancasila perlu ditarik ke atas dank ke bawah. Ditarik ke atas, artinya Pancasila harus mampu mendapatkan pembenaranpembenaran yang bersifat ilmiah-filsafati sehingga selalu diyakini kebenarannya. Sedangkan ditarik ke bawah, artinya Pancasila haruslah mampu "dibumikan" atau direalisasikan dalam praktik hidup dalam kehidupan bermasyarakat, berbangsa dan bernegara.

Pancasila, bagi bangsa Indonesia, berfungsi bukan hanya memberikan wawasan filosofis tentang kehidupan manusia dalam hubungannya dengan sesama manusia, masyarakat/negara, dan Tuhannya, tetapi Pancasila juga berfungsi memberikan pedoman praktik bagaimana seharusnya warga bangsa Indonesia bertindak dalam kehidupan bermasyarakat, berbangsa dan bernegara. Pancasila memang tidak memiliki nilai operasional secara langsung. Operasionalisasi nilai Pancasila, dalam bentuk pedoman atau norma, berlangsung melalui perangkat hukum dan perundang-undangan pada berbagai tingkatan sesuai dengan sistem yang ditetapkan (Djiwandono, 1995: 16).

\section{METODE}

Penelitian ini adalah penelitian pustaka, sehingga metode penelitian yang digunakan adalah metode kualitatif. Peneliti mempergunakan unsur metodis; Pertama adalah interpretasi. Cara ini dipergunakan penulis untuk menerangkan dan mengungkapkan makna dari kedua konsepsi nilai Pancasila yang berfungsi sebagai orthodoksi dan orthopraksis bagi bangsa Indonesia dalam kehidupan bersamanya. Kedua adalah cara abstraksi. Cara ini dipergunakan penelitiuntuk menemukan unsur-unsur penting dan hakiki dari kedua fungsi Pancasila tersebut.Ketiga adalah cara komparasi. Cara ini dipergunakan penulis untuk membandingkan kedua fungsi Pancasila tersebut agar diketemukan kompatibilitasnya dalam rangka pemecahan masalah bangsa Indonesia. Keempat adalah cara heuristika. Cara ini dipergunakan penulis untuk mengungkapkan makna dan penemuan baru dalam kegiatan penelitian.

\section{PEMBAHASAN}

\subsection{Pancasila sebagai Renungan Filsafati}

Tiga guru besar dan ahli filsafat, yaitu Prof. Notonagoro, Prof. Driyarkara dan Prof. Soerjanto Poespowardojo, telah membuktikan bahwa Pancasila mengandung renungan filisofis tentang keberadaan manusia dalam kehidupan bermasyarakat, berbangsa dan bernegara. Ketiga guru besar tersebut memberikan keyakinan akan kebenaran dan kebaikan Pancasila sebagai acuan dalam menjalani hidup bersama bagi setiap manusia dalam kehidupan bermasyarakat, berbangsa dan bernegara. Penulis akan menguraikan secara singkat pandangan dari ketiga filsuf Indonesia tersebut, sebagai berikut :

\subsubsection{Pandangan Driyarkara}

Driyarkara (1959: 5) menegaskan bahwa ajaran Pancasila berpangkal pada kodrat manusia. Substansialitas nilai Pancasila adalah pemanusiawian manusia. Pancasila adalah rumusan eksistensi manusia sebagai manusia, terlepas dari keadaan yang tertentu pada konkretonya. Pancasila sebagai dalil-dalil filsafat adalah 
merumuskan realita manusia di dalam semesta realita. Pancasila memperoleh dasarnya pada eksistensi manusia, lepas dari keadaan hidupnya yang tertentu. Pancasila merupakan filsafat tentang kodrat manusia.

Pancasila memuat ajaran, bahwa keberadaan manusia dalam semesta realita selalu terhubung dan tergantung pada "yang lain", yaitu sesama manusia, alam semesta, dan Tuhan (Driyarkara 1959: 28). Setiap manusia selalu mempunyai hubungan ketergantungan baik secara horizontal (dengan sesama manusia dan alam) dan vertikal (dengan Tuhan). Sejak manusia lahir sampai meninggal dunia keberadaannya terhubung dan tergantung pada manusia lain, alam semesta, dan Tuhan. Konsekuensi dari kodrat keberadaan manusia yang seperti itu, maka manusia dalam menjalankan kehidupannya haruslah menjalin hubungan cinta kasih kepada sesama manusia, alam, dan Tuhan. Gambaran kodrat dan kehidupan manusia tersebut tercermin dalam ajaran Pancasila.

Sudrijanta dan Priyanta (1991/1992: 30-47) menafsirkan pandangan Driyarkara, dengan menyatakan bahwa Pancasila sebagai hukum kodrat yang harus dilaksanakan guna mewujudkan kemanusiaan diri dan sesama. Langkah pertama adalah mewujudkan peri kemanusiaan dengan cara menjalankan ada bersama dengan cinta kasih. Langkah kedua adalah mewujudkan keadilan sosial dengan cara menjalankan kemanusiaan dalam kebersamaan mengusahakan sarana untuk hidup. Langkah ketiga adalah mewujudkan demokrasi dengan cara menjalankan peri kemanusiaan dalam kesatuan karya. Langkah keempat adalah mewujudkan kebangsaan dengan cara melaksanakan peri kemanusiaan dalam hubunganku dengan kesatuan. Langkah kelima adalah mewujudkan gerak kepada sumber ada yang mutlak sebagai dasar pelaksanaan dari peri kemanusiaan, keadilan sosial, demokrasi, dan kebangsaan.
Ajaran Pancasila mewajibkan pada setiap manusia untuk menjalin hubungan cinta kasih kepada Tuhan dengan penuh ketaqwaan dan pengabdian (sila 1). Di samping itu manusia wajib pula menjalin hubungan cinta kasih kepada sesama manusia dalam konteks hidup bermasyarakat, berbangsa dan bernegara (sila 2, 3, dan 4). Akhirnya manusia juga wajib menjalin hubungan cinta kasih dengan alam, memayu hayuning bawana, karena manusia bisa tercukupi kebutuhan hidup pokoknya dari sumber daya alam. Manusia dapat memperoleh kesejahteraan atau kemakmuran bersama (sandang, pangan dan papan) sumbernya dari daya alam (sila 5). Berdasarkan pandangan Driyarkara tersebut dapat ditegaskan, bahwa Pancasila bukan hanya mau menggambarkan realitas kemanusiaan, melainkan juga bahwa kemanusiaan itu harus direalisasikan atau diamalkan.

\subsubsection{Pandangan Notonagoro}

Prof. Notonagoro, yang meneliti Pancasila secara filsafati, telah berhasil menemukan landasan dari Pancasila, yaitu sifat kodrat manusia sebagai makhluk monodualis(yang tersusun atas jiwa dan raga, yang bersifat individu dan makhluk sosial, dan berkedudukan sebagai pribadi mandiri dan makhluk Tuhan). Pancasila adalah filsafat yang sanggup membimbing manusia sesuai kodrat kemanusiaannya, sehingga inti isi mutlak Pancasila yang bersifat abstrak umum universal termasuk nilai objektif. Sedangkan subjektivitas nilai-nilai Pancasila adalah karena ditemukan, diemban, dan dirumuskan dalam ketentuan hukum di Indonesia oleh bangsa Indonesia (Soeprapto, 1994: 1-2). Notonagoro merumuskan teori hierarkhispiramidal ketika menjelaskan tata urutan sila-sila Pancasila. Teori itu menjelaskan, bahwa sila-sila Pancasila mempunyai urutan yang bertata jenjang. Urutan itu tidak bisa dibolak-balik, karena dari sila 1 sampai sila ke 5 merupakan urutan dari 
nilai yang paling luas dan abstrak menuju ke nilai yang paling sempit dan kongkret. Urutan sila-sila Pancasila juga berdasarkan derajat keluhuran nilai. Ketuhanan nilainya paling abstrak namun paling luhur. Seterusnya ke bawah semakin kongkret namun semakin kurang tingkat keluhurannya, sehingga nilai keadilan sosial merupakan nilai yang paling kongkret namun tingkat keluhurannya paling rendah. Urutan dimensi nilai silasila Pancasila adalah religiositas, humanitas, nasionalitas, demokrasi (politik), dan kesejahteraan atau keadilan sosial (ekonomi). Walaupun kesejahteraan sosial, yang berdimensi ekonomi, tingkat keluhuran nilainya paling rendah namun bukan berarti sila paling tidak penting. Kesejahteraan sosial (kebutuhan ekonomi) adalah kebutuhan yang paling kongkret, sehingga goncangan terhadap nilai ini, misalnya terjadi gejolak ekonomi, akan menggoncang nilai yang lebih luhur di atasnya. Gonjangan ekonomi akan menimbulkan goncangan politik. Goncangan politik akan mengganggu persatuan bangsa (nasionalitas). Goncangan terhadap kesatuan bangsa akan menggoncang sendi-sendi nilai kemanusiaan. Akhirnya goncangan atau pelanggaran nilai kemanusiaan akan berakibat goncangan nilai Ketuhanan. Demikian sebaliknya, kalau ekonominya kokoh atau kuat, maka akan memperkokoh pelaksanaan nilai luhur di atasnya (demokrasi, persatuan nasional, kemanusiaan, dan ketuhanan). Notonagoro (1975: 54) menegaskan, bahwa filsafat Pancasila mengandung tiga masalah hidup yang merupakan nilai-nilai hidup kemanusiaan, yang meliputi prinsip-prinsip bagaimana seharusnya manusia menjalin hubungan dengan Tuhan, manusia lain, dan alam semesta.

\subsubsection{Pandangan \\ Poespowardojo}

Soerjanto

Soerjanto Poespowardojo (1989: 28) menegaskan, bahwa Pancasila adalah eksplisitasi kemanusiaan. Pancasila menunjukkan suatu corak pokok yaitu hidup berkemanusiaan. Pancasila adalah ajaran humanistis, yang merupakan refleksi dan usaha agar manusia bertindak manusiawi dan bukan tidak manusiawi. Manusia jangan bertindak yang di luar hakikatnya (inhuman). Lebih lanjut Soerjanto menyatakan, bahwa secara fenomenologis kelima sila Pancasila berlaku bagi setiap manusia. Pada dasarnya tak seorangpun dapat dilepaskan atau dikecualikan dari nilai Pancasila tanpa resiko menyalahi kemanusiaannya. Kesadaran akan kenyataan ini dengan sendirinya mengkaitkan kelima sila sebagai keseluruhan nilai dengan kodrat manusia. Kelima sila merupakan unsur konstitutif kodrat manusia dan inheren padanya. Pancasila mencerminkan nilainilai kodrat yang fundamental sifatnya.

Menurut Soerjanto, Pancasila merupakan eksplisitasi pribadi manusia sebagai totalitas yang mengandung berbagai antinomi dalam dirinya antara individualitas dan sosialitas, materialitas dan spiritualitas, transendensi dan imanensi, eksteriosasi dan interiosasi, yang tidak dilihat secara sektoral dalam salah satu aspek kehidupannya, tetapi dilihat secara integral dengan mengikutsertakan dan memperhatikan segala segi yang membentuk keutuhan pribadi manusia dan mempengaruhinya termasuk problematikproblematik yang ditimbulkan oleh antinomi tertsebut. Bahkan Soerjanto (1989: 69) menegaskan, bahwa menguraikan Pancasila berarti mengeksplisitasikan kodrat manusia.

Ideal Pancasila adalah manusia yang integral, etis dan religius. Dengan kata lain, manusia ditentukan oleh dimensi horizontal dan vertikal. Secara horizontal manusia merupakan kesatuan struktural 
dengan sesama dan lingkungannya, sedangkan secara vertikal ia terarah pada Tuhan sebagai Yang Mutlak. Seluruh tingkah laku manusia mendapatkan kualifikasi dan maknanya sejauh dilaksanakan dalam penghayatan kedua dimensi tersebut.

Soerjanto (1989: 5) menjelaskan lebih lanjut bahwa secara kultural, dasardasar pemikiran dan orientasi Pancasila pada hakikatnya bertumpu pada budaya bangsa. Nilai-nilai Pancasila pada dasarnya terdapat secara fragmentaris dan sporadis dalam kebudayaan bangsa yang tersebar di seluruh kepulauan Nusantara, baik pada abad-abad sebelumnya maupun pada abad keduapuluh, di mana masyarakat Indonesia telah mendapatkan kesempatan untuk berkomunikasi dan berakulturasi dengan kebudayaan lain. Dengan begitu Pancasila mencerminkan nilai-nilai budaya bangsa, baik tradisional maupun modern.

\subsection{Keniscayaan Pancasila sebagai Ideologi Terbuka}

Pancasila sebagai ideologi mempunyai fungsi praktis, karena memberikan pedoman dan mengatur perilaku warganegara Indonesia dalam kehidupan bermasyarakat, berbangsa dan bernegara. Suatu ideologi adalah gagasan atau jalan pikiran yang bertumpu pada suatu filsafat dan merupakan ciri khas suatu kelompok, mempengaruhi kebudayaan keseluruhan kelompok atau bangsa, serta membentuk pranata sosialpolitik bagi kelompok atau bangsa tersebut. Ideologi merupakan komitmen untuk melaksanakan suatu ajaran filsafat. Ideologi petunjuk pelaksanaan atau bermakna praksis bagi filsafat. Pada dasarnya ideologi merupakan bentuk imajinasi sosial yang berfungsi menerangkan keberadaan masyarakat, citacita yang ingin dicapai, serta mendorong ke arah suatu tindakan. Satu ciri bersama yang dimiliki oleh semua ideologi, yaitu mereka merupakan cita-cita dan nilai-nilai yang secara eksplisit dan verbal dirumuskan, dipercayai dan diperjuangkan.R.Kosasih (dalam Bachtiar,
1976: 68) mengidentifikasi ideologi sebagai suatu "program aksi" yang diperuntukkan bagi suatu kelompok atau bangsa. Program aksi itu disusun berdasarkan doktrin tertentu.

$$
\text { Soerjanto Poespowardojo (1989: }
$$

179) mengartikan ideologi sebagai keseluruhan prinsip atau norma yang berlaku dalam suatu masyarakat yang meliputi berbagai aspek, seperti sosialpolitik, ekonomi, budaya, dan hankam. Ideologi adalah keseluruhan prinsip dan norma atau motivasi dalam bertindak, sehingga ideologi menentukan tingkah laku kehidupan sosial, politik, dan ekonomi dalam kehidupan kemasyarakatan dan kenegaraan. Keseluruhan sistem ide itu secara normatif memberikan persepsi, landasan, serta pedoman tingkah laku bagi seseorang atau masyarakat dalam seluruh kehidupannya dan dalam mencapai tujuan yang dicita-citakan. Menurut Roeslan Abdulgani (1978: 2), setiap ideologi , sebagai suatu rangkaian cita-cita yang mendasar dan menyeluruh serta mengkait menjadi satu sistem pemikiran yang logis, adalah bersumber kepada suatu filsafat. Ideologi bertumpu pada asumsi-asumsi dasar. Asumsi dasar suatu ideologi berada pada filsafat yang melandasinya.

Perkembangan ilmu dan teknologi membawa akibat, langsung maupun tidak langsung, terbukanya hubungan antar masyarakat dan kebudayaan pada ranah lokal, nasional, maupun internasional. Akibat kemajuan ilmu dan teknologi pula, khususnya teknologi komunikasi, pola hidup masyarakat berubah dengan begitu cepat. Tidak satupun bangsa dan negara mampu mengisolir diri dan menutup rapat dari pengaruh budaya asing. Demikian halnya terhadap masalah ideologi. Hubungan antar bangsa semakin erat dan luas. Derasnya arus budaya asing yang masuk dengan berbagai aspeknya mengakibatkan terjadinya pergeseran dan perubahan nilai-nilai (Mustopo, 1992: 11 12). 
Keterbukaan dan dinamika kehidupan bermasyarakat, berbangsa dan bernegara memunculkan tuntutan bahwa ideologi Pancasila harus beradaptasi agar tetap terjaga relevansinya sebagai acuan dalam menyelesaikan problem kemasyarakatan dan kenegaraan. Pancasila dituntut mampu menjadi living ideology sehinggadapat mengikuti perkembangan zaman. Agar Pancasila terjaga relevansinya di tengah perkembangan masyarakat dan dunia yang begitu cepat, maka para pemikir dan penyangga ideologi Pancasila selayaknya punya daya refleksi yang mendalam dan sikap keterbukaan yang matang untuk menyerap, menghargai dan memilih nilai-nilai hidup yang tepat dalam memperkaya muatan ideologi Pancasila. Operasionalisasi nilai Pancasila dalam kehidupan bermasyarakat, berbangsa dan Negara haruslah diupayakan secara kreatif dan dinamis.

\subsection{Strategi Beradaptasi Budaya}

Masalah operasionalisasi nilai-nilai dasar Pancasila ke dalam kehidupan praksis bermasyarat dan bernegara bukanlah masalah yang sederhana. Soedjati Djiwandono (1995: 2 - 3) menilai, bahwa masih terdapat beberapa kekeliruan mendasar dalam cara orang memahami dan menghayati Negara Pancasila dalam berbagai seginya. Kiranya tidak tepat membuat sakral dan taboo berbagai konsep dan pengertian, seakanakan sudah jelas betul dan pasti benar, tuntas dan sempurna, sehingga tidak boleh dipersoalkan lagi. Sikap seperti ini membuat berbagai konsep dan pengertian menjadi statis, kaku dan tidak berkembang, dan mengandung resiko ketinggalan zaman, meskipun mungkin benar bahwa beberapa prinsip dasar memang memiliki nilai yang permanen atau abadi.Operasionalisasi nilai Pancasila dituntut selalu mengalami pembaharuan. Hakikat pembaharuan adalah perbaikan dari dalam dan penyerapan nilai dari luar untuk memperkaya isi ideologi Pancasila.
Pembaharuan mengandaikan adanya dinamika internal dalam diri Pancasila. Pancasila sebagai kepribadian dan identitas bangsa Indonesia bukanlah sesuatu yang tertutup tetapi terus dibentuk dalam interaksi dengan kelompok masyarakat bangsa dan pergaulan masyarakat dunia. Dalam konteks bernegara, operasionalisasi Pancasila tidak bisa dilakukan secara langsung, melainkan melalui segala peraturan perundangan yangt berlaku dalam kehidupan bernegara. Pelaksanaan dan kongkretisasi nilai Pancasila dalam kehidupan bernegara tercermin pada seluruh bentuk perundangan, secara berjenjang dari yang tertinggi kedudukan hukumnya sampai yang terendah, yaitu UUD 1945, Ketetapan MPR, UndangUndang atau Peraturan Pemerintah sebagai Pengganti Undang-undang, Peraturan Pemerintah, Keputusan Presiden, dan Peraturan-Peraturan Pelaksana lainnya. Seluruh peraturan perundangan tersebut harus terbuka terhadap amandemen atau judicial review untuk disesuaikan dengan dinamika masyarakat.

Banyak orang mengkawatirkan bahwa derasnya arus modernisasi dan globalisasi bisa melarutkan nilai-nilai tradisi dan identitas bangsa. Pengaruh budaya dan nilai-nilai asing secara negatif menjadi tantangan bagi bangsa Indonesia untuk mempertahankan kepribadian dan identitasnya. Apabila bangsa Indonesia tidak tepat mengambil sikap dalam menghadapi derasnya nilai-nilai asing yang masuk, maka kepribadian dan identitas bangsa memang bisa tererosi atau mengalami pelarutan sehingga berakibat mengendornya kesetiaan terhadap nilainilai Pancasila sebagai kepribadian dan identitas bangsa Indonesia. Pancasila akan kehilangan kewibawaan dan relevansinya sebagai problem solver dalam kehidupan berbangsa dan bernegara (Mulyono, 2011: $5)$.

Sastrapratedja (1996: 8) bersikap optimistis dengan menyatakan bahwa ada indikasi globalisasi tidak melemahkan 
negara kebangsaan tetapi justru memberi peluang untuk memperkuat diri. Kerjasama internasional memungkinkan negara untuk memperjuangkan kepentingan nasional, menjamin keamanan nasional dan mendapat keuntungan lebih besar. Dalam sejarahnya kebudayaan Indonesia dalam berhadapan dengan berbagai kebudayaan asing selalu mampu mengadakan "tawarmenawar" sehingga dapat terbentuk sintesis kebudayaan baru. Bahkan Pancasila sendiri dapat dianggap sebagai hasil interaksi kebudayaan Indonesia dengan pengaruh global, khusunya pengaruh kebudayaan politik modern, seperti kebebasan, demokrasi, negara hukum, dan negara kebangsaan.

Pada era globalisasi, bangsa Indonesia mau tidak mau harus ikut terlibat dalam dialog dengan bangsa-bangsa lain, namun bangsa Indonesia diharapkan tidak tenggelam dan hilang di dalamnya. Proses akulturasi tidak dapat dihindarkan. Kalau bangsa Indonesia memahami identitasnya sendiri sebagai bangsa dengan budaya yang hidup dan terus berkembang, maka globalisasi tidak harus ditakuti sebagai ancaman bagi budaya bangsa Indonesia. Bangsa Indonesia bahkan dituntut berperan aktif dalam pergaulan dunia dan ikut bermain dalam interaksi mondial dalam menentukan arah kehidupan peradaban manusia seluruhnya. Masalah pertemuan kebudayaan bukan masalah mem"filter" atau menyaring tetapi mengolah dalam interaksi yang dinamis, sehingga tercipta sesuatu yang baru. Budaya politik dan jati diri bangsa adalah sesuatu yang harus terus menerus dikonstruksikan, karena mereka bukan kenyataan yang mandeg.

Menghadapi arus medernisasi dan globalisasi dewasa ini, peranan ideologi Pancasila dalam mempersatukan bangsa Indonesia memang mendapatkan ujian. Pancasila dituntut mampu mengadaptasi perkembangan kebudayaan global. Pancasila, melalui para penganutnya, harus mampu melakukan "dialog antar budaya", yaitu membiarkan budaya asing yang menglobal berdampingan dengan budaya asli. Melalui interaksi terus menerus, maka masing-masing budaya akan mendapatkan pelajaran yang berharga. Hasil akhir yang diharapkan dari interaksi itu adalah terpeliharanya cukup diferensiasi dan sekaligis tercegahnya penyeragaman universal (Besar, 1994: 35).

M.Habib Mustopo (1992: 12) berpandangan bahwa dalam menghadapi pertemuannya dengan kebudayaankebudayaan asing, Pancasila harus mampu mengolah dan mengkreasi kebudayaan asing yang masuk sehingga tercipta suasana yang baru dan segar. Dinamika masyarakat memang menuntut perlunya nilai Pancasila terus menerus dikonstruksikan. Kalau Pancasila memang bersifat adaptif, maka Pancasila akan memiliki ketahanan menghadapi arus kuat globalisasi dan bahkan mampu berperan mengarahkan dinamika globalisasi kea rah peradaban yang manusiawi. Pengembangan nilai-nilai Pancasila secara kreatif dan dinamis perlu didorong untuk menghadapi masa depan. Kreativitas dalam konteks ini dapat diartikan sebagai kemampuan untuk mencari alternatif bagi pemecahan masalah di berbagai bidang kehidupan berbangsa dan bernegara.

\section{SIMPULAN}

Kebenaran dan kebaikan Pancasila bagi bangsa Indonesia sudah terjustifikasi melalui berbagai kajian secara ilmiahfilsafati, baik dari aspek historis, yuridis kenegaraan maupun kefilsafatan. Bagi bangsa Indonesia, Pancasila adalah imperatif dan bukan alternatif. Pancasila adalah kebutuhan mutlak untuk mempersatukan bangsa Indonesia yang beragam dalam suku, agama, ras, budaya, maupun golongan. Dalam kedudukannya sebagai ideologi negara, Pancasila menjadi acuan dalam pengambilan kebijakan dan pemecahan masalah dalam kehidupan bermasyarakat, berbangsa dan bernegara. 
masa depan. Akibat lebih jauh, Pancasila akan kehilangan kredibilitasnya sebagai sumber referensi pemecahan masalah kemasyarakatan dan kenegaraan. Pancasila bisa mengalami nasib tragis, seperti komunisme di Eropa Timur, karena ditinggalkan oleh para penganutnya.

Pelestarian nilai Pancasila haruslah diwujudkan melalui upaya untuk tetap memelihara aktualitas nilai-nilai Pancasila sehingga mampu menjawab berbagai tantangan yang timbul dalam masyarakat. Revitalisasi dan reinterpretasi secara terus menerus terhadap Pancasila adalah suatu keniscayaan, agar Pancasila mampu mengikuti perkembangan zaman. Penerusan dan pengembangan nilai-nilai luhur Pancasila dalam segala aspek kehidupan bangsa menuntut adanya strategi kebudayaan, terutama dalam memfilter dan mengolah nilai-nilai asing untuk memperkaya isi kandungan Pancasila.

\section{DAFTAR PUSTAKA}

Abdulgani, Ruslan. 1978. Beberapa Catatan tentang: Ancaman Ideologi terhadap Pancasila.Jakarta: Bahan Ceramah di Lemhanas 10 Mei 1978.

Abdulkadir Besar. 1994. Pancasila dan Alam Pikiran Integralistik (Kedudukan dan Peranannya dalam Era Globalisasi). Yogyakarta: Panitia Seminar "GlobalisasiKebudayaan dan Ketahanan Ideologi" 16-17 November 1994 di UGM.

Azyumardi Azra. 2010. Memulihkan Kesaktian Pancasila.,Kompas, 30 September.
Bachtiar, Harsja W. (Peny.).1976.

Percakapan dengan Sidney Hook tentang MasalahFilsafat. Jakarta: Jambatan.

Djiwandono, Soedjati. 1995. Setengah Abad Negara Pancasila (Tinjauan Kritis Ke Arah Pembaharuan).Jakarta: CSIS.

Driyarkara, N. 1959. Pantjasila dan Religi. Yogyakarta: Makalah disampaikan dalam Seminar Pantjasila Idi Yogyakarta pada tanggal 16 sampai 20 Februari 1959. 
HUMANIKA Vol. 23 No. 2 (2016) ISSN 1412-9418

Pancasila Sebagai Orthodoksi Dan Orthopraksis Dalam Kehidupan Berbangsa Dan Bernegara

Mulyono

Habib Mustopo, M.1992. Ideologi Pancasila dalam Menghadapi Globalisasi dan Era Tinggal Landas. BandunganAmbarawa: Panitia Seminar dan Loka KaryaNasional MKDU Pendidikan Pancasila Dosen-dosen PTN/PTS dan KedinasanPada tanggal 29 - 30 September 1992.

Koento Wibisono. 1988. Pancasila Ideologi Terbuka. Magelang: Panitia Temu KaryaDosen-Dosen PTN Se-Jawa Tengah dan Kopertis Wil.VI.

Liek Wilardjo. 1990.Realita dan Desiderata. Yogyakarta: Duta Wacana University Press.

Mulyono, Drs,M.Hum. 2008. Hakikat dan Dinamika Pancasila. Semarang: Semarang University Press. 2011. Restorasi Pancasila: Suatu Keniscayaan Untuk Mengatasi Masalah-Masalah Bangsa. Semarang: Majalah HUMANIKA Vol.13 Th.VIII Januari-Juni 2011.

Notonagoro. 1975. Pancasila secara Ilmiah Populer. Jakarta: Pantjuran Tudjuh..Pranarka A.M.W. 1985. Sejarah Pemikiran tentang Pancasila. Jakarta: CSIS.
Sartono Kartodirdjo. 1990. Kebudayaan Pembangunan dalam Perspektif Sejarah. Yogyakarta: Gadjah Mada University Press.

Sastrapratedja,M. 1996. Pancasila dan Globalisasi. Magelang: Panitia Seminar NasionalPendidikan Pancasila di Universitas Tidar pada 29-31 Juli 1996.

Slamet Sutrisno. 1986. Pancasila sebagai Metode. Yogyakarta:

Liberty.Snyder, Louis L. 1954. The Meaning of Nationalism. New Brunswick-New Jersey: Rut-ger University Press.

Soeprapto, Sri. 1994. Pemikiran Notonagoro tentang Filsafat Pancasila. Yogyakarta: Panitia seminarNasional "Globalisasi Kebudayaan dan Ketahanan Ideologi" di UGM tanggal 16 17Nopember 1994.

Sudrijanto dan Priyanto. 1991/1992. "Filsafat Pancasila Driyarkarra" dalam Majalah Filsafat Driyarkara,Th.XVIII No.1 Hlm. 30 - 47. Jakarta. 